\title{
¿SON TODAS LAS ÉPOCAS Y CULTURAS HUMANAS \\ IGUALES ANTE DIOS? \\ Husserl y el problema del eurocentrismo*
}

Jesús M. Díaz Álvarez

UNED

A Pedro Alves, que nunca pierde ni la sabiduria ni la sonrisa.

La morale prend son point de départ dans la reconnaissance de l'égalité de tous les hommes en tant qu'êtres raisonnables. Or c'est cela même qui est présupposé dans le dialogue. Si je dialogue avec toi, je te reconnais par lá même comme caplable de vérité (capax veritatis), donc non aliéné à des causes qui contraindraient tont jugement, libre et usant librement de la raison. Les humains qui dialoguent se disent, implicitement, chacun à l'outre: tu es mon égal. Dès lors, s'ils veulent être fidèles à ce qu'ils admettent par le fait du dialogue, ils doivent se reconnaître mutuellement comme égaux et reconnaître qu'il leur appartient de vouloir, ensemble, une société où cette égalité d'essence ait son effectuation par ce que l'on nomme les droits de l'homme, dans leur forme concrète.

Marcel Conche

* Quiero expresar mi más sincero agradecimiento a Gema Trigo por sus comentarios y sugerencias. Este ensayo se ha realizado dentro del marco del proyecto de investigación $\mathrm{La}$ filosofia ante los retos de un mundo plural. Historia, mundo de la vida e interculturalidad, DGICYT HUM2004-03533/FISO. 


\section{Introducción}

El presente ensayo consta de dos partes. En la primera trataré de desentrañar aquello que al decir de Husserl es lo propio y definitorio de la cultura Europea, es decir, aquello que caracteriza su identidad y la diferencia de las demás culturas: el descubrimiento y tematización de la universalidad en sentido estricto. Dicho de otro modo, lo peculiar de la cultura occidental es para Husserl su pretensión de conducir la vida de los humanos según una idea de racionalidad universal. Esta nueva manera de mirar el mundo, que se articula y desarrolla por primera vez en un discurso coherente en Grecia de la mano de la filosofía, será para el padre de la fenomenología un acontecimiento epocal que no sólo singulariza a la cultura Europea frente a cualquier otra, sino que la convierte en el telos de la humanidad, en el fin al que todas las culturas deben tender si en algún momento pretende alcanzarse una convivencia armónica entre los humanos. ${ }^{1}$ En este sentido, el viejo maestro de Prostnitz sostendrá, en expresa contraposición al padre de la historia moderna, el gran Otto von Ranke, que no todas las épocas históricas ni todas las culturas son "iguales ante Dios". Es decir, que la tan extendida tesis relativista, según la cual todas las culturas son equiparables y no pueden ser evaluadas más que dentro de sus propios y peculiares parámetros, es incorrecta y contraria, frente a lo que se pudiera pensar, al ideal de tolerancia.

En la segunda parte, y tomando como base un conocido texto de Derrida, se abordará una acusación que frecuentemente se le hace a la fenomenología Husserliana como consecuencia de la idea precedente: la de ser un pensamiento eurocéntrico. Contra semejante aseveración, se intentará mostrar que el supuesto imperialismo eurocéntrico husserliano no es otra cosa que una defensa de la razón común frente a los intentos de imponer la particularidad de cualquier cultura, sobre todo la europea fáctica, como norma universal.

1 En mi opinión, la carácterización husserliana de Europa como cultura que ha incorporado a su propia entraña la idea de racionalidad universal no tendría porque implicar necesariamente que sólo en ella hubiera acontecido el fenómeno de la razón que aspira a la universalidad. Probablemente en un número importante de culturas no occidentales podemos detectar eso que Celia Amorós, en una expresión feliz, ha denominado "vetas de ilustración". Pero aún siendo esto así, creo que semejante idea no desmentiría la afirmación de Husserl según la cual sólo en Europa se habría tematizado y desarrollado con continuidad de modo explícito el discurso racional - la filosofia - y sólo en ella habría llegado a jugar, por lo tanto, un papel decisivo en su propia configuración como cultura. Es decir, y ese es el meollo de la idea husserliana, sólo en Europa la "veta de ilustración" se habría convertido en tradición, en discurso y práctica esencial que troquelaría aquello que somos. 


\section{La universalidad como seña de identidad de la cultura europea}

Hoy es de sobra conocido entre aquellos que investigan la fenomenología de Husserl que el tópico Natur und Geist es uno de los hilos conductores que vertebra la totalidad de su obra. También es algo sabido la primacía que Husserl concedió al Geist sobre la Natur, puesto que sólo desde aquél, desde una filosofía que estableciese una clara prioridad del segundo sobre la primera, podía evitarse un tratamiento objetivista o naturalista del sujeto, fuente para él de los males que habían aquejado a la Modernidad y, con ella, a la civilización occidental. Primacía en Husserl, por lo tanto, del espíritu sobre la naturaleza. Pero ¿qué significa esto propiamente? Pues ni más ni menos que la asunción de la cultura como aquel elemento que define por excelencia al mundo humano. Husserl le dio a este mundo cultural diferentes nombres a lo largo de su extensa obra, pero uno que hizo fortuna y que posteriormente llegaría a ser emblemático de su filosofía y de otras varias por él influidas es el de Lebenswelt. Ahora bien, fieles a la máxima fenomenológica de no especular sino de describir, la consideración inmediata que cabe hacer sobre ese mundo del espíritu, sobre ese mundo de la vida que abarca la totalidad de las producciones de sentido fruto del genio espiritual de los hombres, es que, en cuanto tal, hemos de constatar que existen, han existido y existirán una enorme diversidad de culturas. No hace falta más que acercarse tímidamente a la ingente producción historiográfica y antropológica para constatar que los seres humanos que nos han precedido, los actuales $\mathrm{y}$, con toda probabilidad, los que nos sucedan, no vivieron, viven o vivirán bajo una tradición homogénea, idéntica. La variabilidad, la relatividad de las formas de vida, de las tradiciones es enorme y va desde la forma de vestir o las maneras de mesa hasta los diferentes dioses en los que se cree. Siguiendo a Ortega, cabría decir que nuestros sistemas de creencias, es decir, aquello que define para nosotros qué es la realidad, en modo alguno son homogéneos. Fácticamente nos enfrentamos, así, a la variabilidad de las culturas. Pero constatado esto, Husserl se va preguntar si tal diferencia radical entre unas culturas y otras implica asumir necesariamente que todas ellas son iguales, que todas ellas, como decía Ranke de las épocas históricas, son "iguales ante Dios". Esto es, por otra parte, la postura que mantienen los historicistas o los relativistas culturales. Para ellos, nos dice Husserl en un texto del "Origen de la geometría", "todo pueblo, grande o pequeño, tiene su mundo en el que todo concuerda, tanto si es en la forma mágico-mítica como en la racionaleuropea, y todo se deja explicar completamente. Todo $<$ pueblo> tiene su "lógica" y, según eso, si esta se explicitara en proposiciones, 'su' apriori". 2 En tal sentido, es importante recordar que desde esta posi-

2 E. Husserl, "Die Frage nach dem Ursprung der Geometrie als Intentional historisches Problem", en, E. Husserl, Die Krisis der europäischen Wissenschaften und die transzendentale Phänomenologie. Eine Einleitung in die phänomenologische Philosophie, Kluwer, 
ción no podemos establecer ninguna jerarquía racional de unos mundos sobre otros. Cada pueblo tiene, como se termina de afirmar, $s u$ lógica, $s u$ racionalidad, $s u$ a priori; en suma, cada mundo tiene $s u$ cultura, que no puede ser evaluada desde la de cualquier otro, y esto tanto a nivel de la razón teórica como de la razón práctica. Por eso, la forma racional-europea, como aquí se menciona, no es ni mejor ni peor, no dice más o menos verdades acerca de los humanos y su mundo que la mítico-mágica. Es más, nociones como la de verdad o bien tendrían sentido sólo dentro de la respectiva cultura que previamente ha producido su definición. Pues bien, Husserl en absoluto va a compartir la argumentación historicista o relativista, dirigiendo una gran parte de sus esfuerzos filosóficos a neutralizarla. ${ }^{3}$

Como podemos deducir por la cita previa del "Origen de la geometría", Husserl va a hacer con las diversas culturas dos grandes bloques. De un lado va a situar a la racionalidad europea y de otro a lo que arriba se ha denominado, de modo un tanto impreciso, forma o racionalidad mágico-mítica, que en otros lugares, por ejemplo, en la "Conferencia de Viena", tilda como culturas de carácter práctico, mítico-religiosas o prefilosóficas. ${ }^{4}$ La pregunta que tenemos ahora que abordar, que surge ante este planteamiento es, ¿qué hace a la cultura y racionalidad europeas diferente de todas las demás? o, enunciado de otro modo, ¿en qué consiste la identidad de la cultura europea como contradistinta de la que encarnan las culturas de carácter práctico o mítico-religiosas? Para Husserl, aquello que es lo propio y peculiar de la cultura occidental es su pretensión de conducir la vida de los humanos según una idea de racionalidad universal. En efecto, lo que se alumbra en Grecia o, mejor dicho, lo que se hace explícito por primera vez en Grecia de la mano de la filosofía es un modo de pensar que trasciende todo aquello que es Zeitgebunde, es decir, ligado a un tiempo o mundo particulares. La cultura europea parece ser la única en la que se da la curiosa paradoja de pretender trascender de modo radical y hasta sus últimas consecuencias su propio marco de justificación espacial y temporal. Es decir, las cosas no valen por ser europeas - el criterio de legitimidad no está vinculado al grupo, el tiempo y la tradición en la que se vive -, sino que son aceptadas porque son susceptibles de ser asumidas por cualquiera en un proceso racional dialógico y ofrecen una mejor descripción del mundo y del espíritu humano. En tal sentido, la cultura europea se diferencia del resto. Su modo de funcionar no es hacia dentro, hacia el pueblo, nación o grupo que posee semejante tradición, sino hacia fuera. Ello supone la constante crítica de los propios presupuestos, de la propia tradición. No se trata de

3 Para un análisis muy penetrante del relativismo vinculado a la noción de mundo de la vida, cf. A. Gurwitsch, "The Life-World and the Phenomenological Theory of Science", en A. Gurwitsch, Phenomenology and the Theory of Science, Northwestern University Press, Evanston, 1974, pp. 3-32.

4 Cfr., E. Husserl, "Die Krisis des europäischen Menschentum und die Philosophie", en E. Husserl, op., cit., p, 329 y ss 
fomentar y proteger a toda costa los dogmas heredados, sino, y si se me permite la expresión, de ir a degüello sobre ellos. No en vano, en una de las muchas frases felices que abundan en la obra de Ortega, se nos dice que la filosofía, encarnación para Husserl, como ya sabemos, de la racionalidad occidental, es la "tradición de la intradición". Por todo lo visto aquí, no es de extrañar que Husserl designe a la cultura europea no sólo como la cultura de la idealidad, de la theoría o de la crítica, sino también, y en íntima relación con ello, como la cultura de la autonomía y la absoluta responsabilidad del sujeto.

\section{A vueltas de nuevo con el eurocentrismo. La impugnación "eurocén- trica" del eurocentrismo}

Hoy en día una de las peores acusaciones que se le pueden hacer a un filósofo es la de favorecer, legitimar o inspirar con su pensamiento lo que se ha dado en llamar eurocentrismo. El eurocentrismo, en esta versión negativa, no es otra cosa que interpretar a los demás pueblos desde, y subrayo esto, la propia particularidad de la cultura europea. El efecto inmediato de semejante actitud ha sido, en el plano teórico, la negación de cualquier tipo de racionalidad a las demás culturas y, en el plano político, el colonialismo, con sus terribles consecuencias de destrucción y miseria. En suma, el eurocentrismo es el no reconocimiento del valor del otro en tanto que otro distinto del europeo y su posterior aniquilamiento o desvalorización como ser humano. Pues bien, Husserl ha sido un pensador al que con bastante frecuencia se le ha tildado de eurocéntrico. Y a alguien le podría parecer que desde los términos en los que antes se ha tematizado la cultura occidental en su filosofía de la historia tales acusaciones se ajustan completamente a la verdad. El tema es muy complicado y tiene muchas derivas en las que no puedo entrar, pero, a pesar de ello, sí quiero presentar las líneas fundamentales que sustentan semejante acusación, para, a renglón seguido, intentar rebatirlas.

Creo que Husserl no es un pensador eurocéntrico en el sentido imperialista y colonialista con el que semejante concepto se usa habitualmente. Más bien al contrario, su respeto por el otro y por la racionalidad de las múltiples culturas en las que se asienta, así como el reconocimiento de su humanidad, son temas medulares en su filosofía. Pero semejante reconocimiento no le va a impedir jerarquizar o, lo que es lo mismo, discriminar entre las diversas culturas según el modelo de lo que en la primera parte he caracterizado muy esquemáticamente como aquello que conforma la identidad de la cultura europea: la racionalidad universal. Es decir, lo que voy a defender a continuación, por paradójico que sea, es el no eurocentrismo de Husserl en virtud de su defensa de Europa como cultura universal.

$\mathrm{Y}$ voy a tratar este asunto a partir de un texto, en concreto, de una extensa nota a pie de página muy polémica que Jacques Derriḍa en su libro De 
l'esprit: Heidegger et la question dedica a Husserl y su exclusión de los gitanos, esquimales e indios del Geist europeo. Dada su extensión, la nota sólo puede ser citada en sus partes más relevantes. Por otro lado, también quiero advertir que lo que sigue no pretende ser, en modo alguno, una interpretación global del libro, sino que de lo que se trata es, mas bien, de usar este texto como ilustración de la crítica a la fenomenología de Husserl en tanto que pensamiento eurocéntrico e, incluso, racista. Y dice Derrida: "Esta figura de Europa es precisamente 'espiritual' en la medida en que no se le asigna ya una circunscripción geográfica o territorial... Esta determinación 'espiritual' de la humanidad europea ¿puede conciliarse con la exclusión de los "esquimales, de los indios de los circos ambulantes o de los gitanos en eterno vagabundeo por Europa?". En efecto, inmediatamente después de haber hecho la pregunta “¿Cómo se caracteriza la figura espiritual de Europa?”, Husserl añade: “en el sentido espiritual, pertenecen a Europa de modo evidente los dominios ingleses, los Estados Unidos, etc., pero no los esquimales o los indios de las exposiciones de feria o los gitanos que vagabundean permanentemente en Europa". La conservación de los dominios ingleses en la Europa espiritual testimoniaría, de forma bastante irrisoria, considerando la comicidad que pesa sobre este siniestro pasaje, una inconsecuencia filosófica cuya gravedad se mide en dos dimensiones: 1. Para salvaguardar los dominios ingleses, el poder y la cultura que representan, habría que distinguir, por ejemplo, entre los indios buenos y los malos. Esto no parece muy "lógico", ni desde el punto de vista de la lógica "espiritualista" ni desde el de la racista. 2. Este texto fue leído nada menos que en 1935 en Viena. [Y líneas más adelante continúa Derrida]: "A propósito del espíritu y de Europa, ya que es lo único que nos interesa aquí, no habría que olvidar lo que ciertas 'víctimas', [y se está refiriendo a Husserl], han escrito y pensado. Y siempre en nombre del espíritu. ¿Habría suscrito Heidegger lo que Husserl dijo sobre los gitanos? ¿Habría expulsado a los no 'arios' fuera de Europa como lo hizo aquel que, sin embargo, tampoco era 'ario' él mismo, [es decir, Husserl]?".

He de confesar que cuando leí esta nota tan tremendamente dura para con Husserl mi desconcierto fue mayúsculo. Pues hay aquí no sólo una acusación clara de eurocentrismo, palabra que por cierto emplea Derrida en su texto aun-

5 J. Derrida, De l'espirit: Heidegger et la question, Galilée, Paris, 1987. pp. 94-96. De este texto hay traducción castellana de Manuel Arranz: J. Derrida, De espiritu: Heidegger y la pregunta, Pre-textos, Valencia, 1989. Pp. 96-99. La respuesta que Derrida va a dar a las preguntas con las que finaliza el escrito que citamos es que no, que Heidegger no habría suscrito ese juicio husserliano sobre los gitanos ni los habría expulsado de Europa, atribuyendo semejante negativa a su alejamiento de la noción de espíritu que el propio pensador francés parece querer ligar a la tradición filosófica occidental y al idealismo transcendental husserliano como una expresión última de la misma. Si no lo interpreto mal, el profesor Reyes Mate ha asumido en España una parte sustancial de los argumentos de Derrida contra Husserl. Cf. Reyes Mate, Heidegger y el judaismo. Y sobre La tolerancia compasiva, Anthropos, Barcelona, 1998. pp. 24-25. 
que en una parte que yo no he citado, sino que creo que en ella se apunta a que en Husserl, en su noción de Europa como Geist, habría una exclusión radical del otro en virtud de una lógica oculta que es, tomando prestada cierta terminología que aquí emplea el pensador francés, a veces de carácter espiritualista y a veces de carácter racista. Es más, creo que para Derrida ambas lógicas tendrían una cierta confluencia, siendo su consecuencia la misma: la exclusión radical del otro.

A efectos pedagógicos y de defensa de mi tesis, completamente contraria a la de gran filósofo francés, voy seguidamente a distinguir y dar contenido claramente a ambas lógicas, aunque en el desarrollo de mis contraargumentaciones se verá la primacía de lo que yo llamo "lógica espiritual".

La primera lógica, la espiritualista, implica excluir al otro en virtud de la propia particularidad espiritual de la cultura europea, que se impondría a las otras culturas, también particulares, por la fuerza y sin apelar a razones. La segunda, la lógica racista, como es tristemente bien sabido, apela a que una raza es superior a las demás. Esta lógica racista parece pesar mucho, asombrosamente, en el texto de Derrida, cuando, por ejemplo, se pregunta si Heidegger habría excluido a los gitanos, identificados después como los no arios, de Europa. En cualquiera de los dos casos, de las dos lógicas que parecen estar detrás del pensamiento de Husserl para excluir a los gitanos, indios o esquimales de Europa, nos enfrentamos con una fortísima acusación que tendría su culminación en la tesis derridiana de que un pensamiento como el de Husserl, y éste como encarnación muy relevante de la tradición occidental, habría conducido al totalitarismo y, más en concreto, dentro de la Alemania de la época, a la Shoa. Por otro lado, en otra parte de la nota, también apunta Derrida que "la cuestión del animal no anda lejos", aludiendo con ello a la diferenciación del Geist europeo frente al de los otros pueblos, en este caso, los esquimales, los indios y los gitanos. Se insinuaría, pues, que estos pueblos, y los no occidentales en general, estarían para Husserl más cerca de la animalidad o serían más similares a los animales.

Pero analicemos todo esto con un poco más de detalle y hagámoslo formulándonos tres preguntas. Primera, ¿hay verdaderamente en Husserl, en su noción de Europa, del Geist europeo, una exclusión radical del otro no europeo a la que podría subyacer una "lógica racista" o "espiritualista" que le lleva a incluir en el citado Geist a los dominios ingleses y a los Estados Unidos pero no a los gitanos? O formulado de una manera complementaria, ¿hay en Husserl una "inconsecuencia filosófica" basada en una soterrada "lógica racista" o "espiritualista" cuando dice que los gitanos, esquimales o indios no pertenecen a Europa? La segunda cuestión es, ¿se da en el pensamiento de Husserl una cierta asimilación entre las culturas no europeas y la animalidad? Y ya, por último, la tercera, ¿es el idealismo transcendental que sustenta el Geist europeo, como parece decir Derrida, un pensamiento totalitario, genocida o que ha conducido a la Shoa? 
Para aclarar estas trascendentales cuestiones, lo mejor es repetir de nuevo el supuestamente "siniestro" texto de Husserl al que se refiere y cita Derrida. El pasaje aludido sobre los indios, esquimales y gitanos procede de la conocida "Conferencia de Viena", pronunciada por Husserl en dicha ciudad en mayo de 1935 bajo el significativo título de "La crisis de la humanidad europea y la filosofia". Dice lo siguiente: "Formulamos la pregunta: ¿cómo se caracteriza la forma espiritual de Europa? Es decir, Europa, entendida no geográfica o cartográficamente, como si se debiese circunscribir al ámbito de los hombres que conviven aquí territorialmente en calidad de humanidad europea. En el sentido espiritual, pertenecen a Europa de modo evidente los dominios ingleses, los Estados Unidos, etc., pero no los esquimales o los indios de las exposiciones de feria o los gitanos que vagabundean permanentemente en Europa. Bajo el titulo 'Europa' se trata aquí, evidentemente, de la unidad de un vivir, obrar, crear espirituales..."

Lo primero que nos dice Husserl en el parágrafo precedente es, como Derrida reconoce, que Europa no designa una caracterización geográfica. No se es europeo por habitar aquello que designamos geográficamente como Europa. $\mathrm{Y}$ es para mostrar esto, para desmentir el argumento geográfico, y no por ninguna lógica racial implícita, por lo que Husserl se remite, precisamente, a los Estados Unidos o a los dominios ingleses. Porque si Europa fuera una zona geográfica reducida al continente, jamás los americanos o los australianos, por poner sólo dos ejemplos, podrían llamarse "europeos". Por esa misma razón, los gitanos que vagabundean en el territorio físico del continente europeo o los indios o esquimales que se exhiben en las ferias de la Europa geográfica y que pueden llevar varias generaciones ahí no son, sin más, "europeos". Y es que, para Husserl, Europa, como ya sabemos, es una categoría espiritual, una manera peculiar de ver el mundo y de comportarse en él, caracterizada por esas ideas de infinitud, de crítica permanente a la tradición, de autonomía, de idealidad o de plena autorresponsabilidad. En suma, Europa encarna para Husserl, lo repito una vez más, la idea de racionalidad universal, es decir, la idea del logos común, que por su propia definición puede ser alcanzado y asimilado por cualquiera por el mero hecho de ser un humano. Y desde semejante punto de vista, es verdad que los gitanos, los indios o los esquimales no son espiritualmente europeos en la medida en que sus culturas no responden al patrón universalista y permanecen atadas a la férrea cosmovisión particularista que su tradición mítico-religiosa les impone. No hay en Husserl, por otra parte, ninguna alusión a la raza, ni al acceso a la cultura europea en virtud de la raza. No hay, así, en su pensamiento ninguna "inconsecuencia filosófica" a la hora de afirmar que, culturalmente, los gitanos, indios o esquimales no pertenecen al

6 E. Husserl, "Die Krisis des europäischen Menschentums und die Philosophie", en E. Husserl, Die Krisis der europäischen Wissenschaften und die transzendentale Phänomenologie. Eine Einleitung in die phänomenologische Philosophie. Kluwer, Den Haag, 1976 (Husserliana VI). P. 318-319. 
Geist europeo. Solo habría inconsistencia si el propio Husserl, una vez afirmado el carácter espiritual de la condición de europeo, cerrara ese espacio a los otros no europeos, en este caso, en virtud de su raza, cosa que está muy lejos, ni siquiera, de sugerir. Esto en cuanto a la inconsistencia filosófica fruto de la "lógica racial".

Vayamos ahora a lo que Derrida ha denominado "inconsistencia filosófica" con base en la "lógica espiritual". Y una vez entendido lo que dice Husserl, se ve mucho más claramente el error que cometen aquellos que como el pensador francés acusan a Husserl de eurocéntrico desde este punto de vista. Con semejante "lógica espiritual" se designa, insisto de nuevo, la anulación del otro que Husserl cometería en la medida en que una cultura particular más, la europea, juzga y condena a las demás culturas particulares exclusivamente en razón de su poderío material y tecnológico, es decir, de la razón de la fuerza. Sin embargo, lo que el autor de las Ideas está reivindicando con la palabra Europa es la razón común, la fuerza de la razón, la potencialidad de un discurso, es verdad, nacido en occidente, pero que no encarna, y esto es lo decisivo, la particularidad de occidente. Es precisamente esta elevación por encima de la propia facticidad y peculiaridad históricas lo que le permite criticar la propia cultura en la que ha nacido. Porque, no se olvide, la crítica al colonialismo, al imperialismo, al eurocentrismo, en suma, la crítica a algunos de los peores males causados por la cultura occidental, se hacen muchas veces dentro del marco de la tradición crítica y bajo los ideales de justicia que Husserl subsume en su idea de Europa. Asumir la escucha del otro, intentar atender y comprender sus razones en una discusión sin supuestos, es decir, que no pueda cerrarse por motivos extrarracionales, es ya formar parte, aunque de modo incipiente, de ese Geist europeo. Teniendo esto presente, sólo podríamos criticar el eurocentrismo perverso que anula al otro siendo eurocéntricos en este segundo sentido. Dicho de otro modo, cuando Husserl reivindica la cultura europea, percibe claramente que en modo alguno todo lo que entendemos por cultura occidental cae bajo el patrón de lo que él ha estado rotulando como tal. Occidente tiene un gran número de componentes en su tradición que son tan particulares como los de cualquier otra cultura: el vestir, el modo de alimentarse, las creencias religiosas, la composición familiar, algunas formas de gobierno, etc. En ellas no hay nada que probablemente sea susceptible de ser universalizado. Todo ello es, por usar una distinción categorial de Javier San Martín, un conjunto de formas de vida étnicas, particulares, mientras lo que Husserl propiamente define como cultura occidental es precisamente aquello que se eleva por encima de esas peculiaridades, iguales a las de las otras culturas, y conforma lo no étnico ${ }^{7}$ - que podríamos resumir en los ideales de verdad, bien y justicia, en suma, en los ideales que marcan la razón teó-

7 Cf. Javier San Martín, “¿Es Europa una idea etnocéntrica?”, en VV.AA., La idea de Europa. Una aproximación filosófica, Valencia, 1991, pp. 35-53. 
rica y la razón práctica - Es desde este punto de vista desde el que se nos dirá que la cultura europea es el Telos de la humanidad, aquello a lo que deben tender la totalidad de las culturas, la occidental fáctica también, si queremos aspirar a una humanidad regida por semejantes ideales de verdad, bien y justicia. $^{8}$

Puestas así las cosas, parece muy difícil mantener que Husserl niegue el acceso al espíritu europeo a los no occidentales, tanto en virtud de una supuesta "lógica racista" como "espiritualista". Más bien es todo lo contrario. Por ser lo común, todos tienen acceso. Desde luego, en el fragmento en el que Derrida se basa para lanzar su crítica, ni siquiera haciendo enormes piruetas interpretativas puede deducirse, en modo alguno, lo que él concluye. Por lo demás, y en coherencia con lo expuesto, son muchos los lugares, en la propia "Conferencia de Viena" y en otros textos, donde el fundador de la fenomenología manifiesta lo contrario.

¿Y qué decir ahora, dentro ya de la segunda pregunta, de la sugerencia derridiana según la cual habría en Husserl una cierta tendencia a asimilar el mundo de los esquimales, gitanos o indios con la animalidad? El fundador de la fenomenología tampoco mantiene en ningún lugar nada parecido. Otra vez su posición aquí es la contraria a la que se le quiere atribuir: "La razón es un título vasto. El hombre según la buena y vieja definición, es el ser viviente racional, y en este sentido amplio también el Papua es hombre y no animal. También él tiene sus fines y procede reflexivamente, sopesando las posibilidades prácticas. Las obras y métodos, a medida que surgen, van formando la tradición, y pueden ser siempre comprendidos de nuevo en su racionalidad." Es decir, el Papua es para Husserl un humano, un ser capaz de ejercer la facultad de la razón y, lo que es más importante, capaz de crear un mundo que es racional en la medida en que se adapta a sus necesidades. Además, es precisamente porque compartimos con él la condición humana de la racionalidad por lo que podemos comprender ese mundo, la tradición que él ha conformado. ${ }^{10}$ Lo mismo va a decirnos de las grandes culturas orientales. Son mundos ricos y complejos, detentadores de un enorme refinamiento que muestra el genio y la capacidad racional de los humanos. Ahora bien, el que Husserl reconozca ese común componente de racionalidad a todos los humanos y a los mundos prodigiosos que construyen $\mathrm{y}$, por lo tanto, también a las culturas

8 Sobre este tema, cf. J. M. Díaz Álvarez, Husserl y la historia. Hacia la función práctica de la fenomenología, UNED, Madrid, 2003. Para una lectura crítica y penetrante de la tesis husserlina sobre Europa, cf. E. Holenstein, "Europa und die Menschheit. Zur Husserls kulturphilosophischen Meditationen", en E. Holenstein, Kulturphilosophische Perspektiven, Suhrkamp, Frankfurt, 1998, pp. 230-253. El artículo de Holenstein está estrechamente vinculado a otro no menos excelente de Klaus Held: K. Held "Husserls These von der Europäisierung der Menschheit”, en Ch. Jamme und O. Pöggeler (Hrsg.), Phänomenologie im Widerstreit, Suhrkamp, Frankfurt, 1989, pp. 13-39. 
prefilosóficas, no significa una equiparación de todas las tradiciones culturales. Así, para el filósofo alemán, el relativismo cultural y su atribución de racionalidad a todas las culturas es un punto de partida, pero no de llegada. La consideración sobre la racionalidad de las culturas debe ir acompañada por aquello que Europa representa: la cultura de la racionalidad ${ }^{11}$.

Y ya para terminar, ¿puede decirse, sin más, que el pensamiento husserliano es uno de los responsables de Auschwitz? La verdad es que cuando leía el texto de Derrida fue ésta una de las cosas que más me llamó la atención. No porque haya que tener tabúes a la hora de analizar el pensamiento o las consecuencias del pensamiento de un gran filósofo, sino porque la elección de confrontar a ese respecto a Husserl con Heidegger me parece poco aceptable a la luz de la biografía de ambos autores. Pues la biografía de un filósofo, su decurso vital, sobre todo en momentos de gran trascendencia ético-política, nunca está completamente separada de su filosofar. En cualquier caso, y hasta donde yo alcanzo, me resulta muy difícil vincular el pensamiento de Husserl con la Shoa. Su idea de la superioridad del ideal que encarna Europa en ningún caso es compatible con el uso de la violencia como medio de encaminar a nadie por la senda de la verdad, el bien o la justicia. Esta forma de violencia no sería más que una impugnación de raíz de aquello que pretendía el viejo maestro con su pensamiento, que no era otra cosa que recuperar, en tiempos sombríos, el lógon didónai, el dar y recibir razones.

\section{TEXTO DE DERRIDA}

Esta figura de Europa es precisamente 'espiritual' en la medida en que no se le asigna ya una circunscripción geográfica o territorial... Esta determinación "espiritual" de la humanidad europea ¿puede conciliarse con la exclusión de los "esquimales, de los indios de los circos ambulantes o de los gitanos en eterno vagabundeo por Europa?". En efecto, inmediatamente después de haber hecho la pregunta " ¿Cómo se caracteriza la figura espiritual de Europa?", Husserl añade: "en el sentido espiritual, pertenecen a Europa de modo evidente los dominios ingleses, los Estados Unidos, etc., pero no los esquimales o los indios de las exposiciones de feria o los gitanos que vagabundean permanentemente en Europa". La conservación de los dominios ingleses en la Europa espiritual testimoniaría, de forma bastante irrisoria, considerando la comicidad que pesa sobre este siniestro pasaje, una inconsecuencia filosófica cuya gravedad se mide en dos di-

"Cf. James Hart, "The Rationality of Culture and the Culture of Rationality", in Philosophy East and West, 42, 643-664. Para un análisis más detallado de Europa como cultura de la racionalidad puede verse, también, Jesús M. Díaz Álvarez, "The Foundation of Morality and Normative-Cultural Differences. A Phenomenological Approach", en B. Penas Ibáñez \& $M^{a}$. C. López Sáenz (eds), Interculturalism. Between Identity and Diversity, Peter Lang, Bern, 2006, pp. 109-130. 
mensiones: 1. Para salvaguardar los dominios ingleses, el poder y la cultura que representan, habría que distinguir, por ejemplo, entre los indios buenos y los malos. Esto no parece muy "lógico", ni desde el punto de vista de la lógica "espiritualista" ni desde el de la racista. 2. Este texto fue leído nada menos que en 1935 en Viena". [Y líneas más adelante continúa Derrida]: "A propósito del espíritu y de Europa, ya que es lo único que nos interesa aquí, no habría que olvidar lo que ciertas 'víctimas', [y se está refiriendo a Husserl], han escrito y pensado. Y siempre en nombre del espíritu. ¿Habría suscrito Heidegger lo que Husserl dijo sobre los gitanos?, ¿Habría expulsado a los no 'arios' fuera de Europa como lo hizo aquel que, sin embargo, tampoco era 'ario' él mismo, [es decir, Husserl] ${ }^{12}$

\section{TEXTOS DE HUSSERL}

Formulamos la pregunta: ¿cómo se caracteriza la forma espiritual de Europa? Es decir, Europa, entendida no geográfica o cartográficamente, como si se debiese circunscribir al ámbito de los hombres que conviven aquí territorialmente en calidad de humanidad europea. En el sentido espiritual, pertenecen a Europa de modo evidente los dominios ingleses, los Estados Unidos, etc., pero no los esquimales o los indios de las exposiciones de feria o los gitanos que vagabundean permanentemente en Europa. Bajo el titulo "Europa" se trata aquí, evidentemente, de la unidad de un vivir, obrar, crear espirituales... ${ }^{13}$

La razón es un título basto (nos dice). El hombre según la buena y vieja definición, es el ser viviente racional, y en este sentido amplio, también el Papua es hombre y no animal. También él tiene sus fines y procede reflexivamente, sopesando las posibilidades prácticas. Las obras y métodos, a medida que surgen, van formando la tradición, y pueden ser siempre comprendidos de nuevo en su racionalidad. $^{14}$

12 J. Derrida, De l'espirit: Heidegger et la question, Galilée, Paris, 1987. Pp. 94-96. De este texto hay traducción castellana de Manuel Arranz: J. Derrida, De espiritu: Heidegger y la pregunta, Pre-textos, Valencia, 1989, pp. 96-99.

13 E. Husserl, "Die Krisis des europäischen Menschentums und die Philosophie", en E. Husserl, Die Krisis der europäischen Wissenschaften und die transzendentale Phänomenologie. Eine Einleitung in die phänomenologische Philosophie. Kluwer, Den Haag, 1976 (Husserliana VI). pp. 318-319.

${ }^{14}$ E. Husserl, op., cit., pp. 337-338. 


\begin{abstract}
La presente intervención va constar de dos partes. En la primera, trataré de desentrañar aquello que al decir de Husserl es lo propio y definitorio de la cultura Europea, es decir, aquello que caracterizaría su identidad y la diferenciaría de las demás culturas: el descubrimiento de la universalidad en sentido estricto. $\mathrm{O}$ dicho de otro modo, para Husserl, aquello que es peculiar de la cultura occidental es su pretensión de conducir la vida de los humanos según una idea de racionalidad universal. Esta nueva manera de mirar el mundo, que se articula y desarrolla por primera vez en un discurso coherente en Grecia de la mano de la filosofia, será para el padre de la fenomenología un acontecimiento epocal que no sólo singulariza a la cultura Europea frente a cualquier otra, sino que la convertirá en el telos de la humanidad, en el fin al que todas las culturas deben tender si en algún momento pretende alcanzarse una convivencia harmónica entre los humanos. En este sentido, el viejo de maestro de Prostnitz sostendrá, en expresa contraposición al padre de la historia moderna, el gran Otto von Ranke, que no todas las épocas históricas ni todas las culturas son iguales ante Dios, es decir, que la tesis relativista tan en boga hoy en día según la cual todas las tradiciones o formas de vida son equiparables y no pueden ser evaluadas más que dentro de sus propios y peculiares parámetros es incorrecta y contraria, frente a lo que se pudiera pensar, al ideal de tolerancia.

En la segunda parte de la ponencia, y tomando como base un conocido texto de Derrida, se abordará una acusación que frecuentemente se le hace a la fenomenología Husserliana a la luz de la tesis precedente: la de ser un pensamiento eurocéntrico. Contra semejante aseveración, se intentará mostrar que el supuesto imperialismo eurocéntrico husserliano no es otra cosa que una defensa de la razón común. Y ello, frente a los intentos de imponer la particularidad de cualquier cultura, sobre todo la europea fáctica, como norma universal.
\end{abstract}


